\title{
Phylogenetic divergence between the obligate luminous symbionts of flashlight fishes demonstrates specificity of bacteria to host genera
}

Tory A. Hendry ${ }^{\star \dagger}$ and Paul V. Dunlap

Department of Ecology and Evolutionary Biology, University of Michigan, 830 North University Ave., Ann Arbor, MI 48109-1048, USA.

\section{Summary}

The luminous bacterial symbionts of anomalopid flashlight fishes, which appear to be obligately dependent on their hosts for growth, share several evolutionary patterns with unrelated obligate bacteria. However, only one flashlight fish symbiont species has been characterized in detail, and it is therefore not known if the bacteria from other anomalopid species are highly divergent (a pattern common to obligate symbionts). Unlike most obligate symbionts, the bacteria symbiotic with anomalopids are extracellular and spend time outside their hosts in the environment, from which they are thought to colonize new host generations. Environmental acquisition might decrease the likelihood of bacterial divergence between host species. We used phylogenetic analysis to determine the relatedness of symbionts from different anomalopid host species. The symbionts of hosts in the genus Photoblepharon were resolved as a new species, for which we propose the name 'Candidatus Photodesmus blepharus'. Furthermore, different genera of anomalopids were found to harbour different species of bacteria, even when the hosts overlapped in geographic range. This finding suggests that the divergence between bacterial species is not the result of geographic isolation. The specificity of symbionts to host genera is consistent with obligate dependence on the host and has implications for symbiont transmission.

\section{Introduction}

Luminous bacteria of the Gammaproteobacteria family Vibrionaceae engage in mutualistic symbioses with multi-

Received 23 October, 2013; accepted 9 December, 2013. *For correspondence. E-mail thendry@umich.edu; Tel. (+1) 734615 9099; Fax (+1) 734763 0544. 'Present address: Department of Environmental Science, Policy, and Management, University of California, 130 Mulford Hall, Berkeley, CA 94720-3114, USA. ple lineages of marine fish and squid (Herring and Morin, 1978; Dunlap et al., 2007; Dunlap and Urbanczyk, 2013). Most of these associations involve facultatively symbiotic bacteria that maintain free-living populations in diverse habitats (Lee and Ruby, 1994, Thompson et al., 2005; Reen et al., 2006; Dunlap et al., 2007; Preheim et al., 2011; Dunlap et al., 2012). The symbionts of anomalopid flashlight fish appear to be an exception to this trend; genomic evidence demonstrates that the anomalopid symbiont 'Candidatus Photodesmus katoptron' shares several evolutionary patterns with intracellular obligate mutualists and is likely to be obligately dependent on its host for growth (Hendry et al., in press). These patterns include genome reduction due to gene loss, high AT nucleotide content and a high evolutionary rate (Moran, 1996; Woolfit and Bromham, 2003; Wernegreen and Moran, 2004; Hendry and Dunlap, 2011; McCutcheon and Moran, 2012; Hendry et al., in press). Strict vertical transmission and high levels of genetic drift in obligate symbionts are thought to cause the patterns mentioned above and also typically to lead to bacterium-host codivergence and increased phylogenetic distance between bacteria from different hosts (Clark et al., 2000; Wernegreen, 2002; Bright and Bulgheresi, 2010; Sachs et al., 2011). Because only one species of anomalopid symbiont has been characterized in detail, it is not known if different anomalopid host species harbour divergent bacterial species, as is the case with known obligate symbionts.

Facultative luminous symbionts do not codiverge with hosts. Instead, many symbionts form associations with multiple unrelated host species while remaining closely related at the species level (Dunlap et al., 2007; Kaeding et al., 2007). Some examples of genetic variation have been found between luminous bacteria from hosts of different species or geographic location (Ast et al., 2007; Mandel et al., 2009). However, the amount of genetic divergence found in these cases is small compared to that observed in obligate symbionts, likely because facultatively symbiotic luminous bacteria are environmentally acquired by each host generation from free-living populations rather than being vertically transmitted (Leis and Bullock, 1986; Lee and Ruby, 1994; Nyholm and McFall-Ngai, 2004; Dunlap et al., 2007; 2008; 2012). Like 


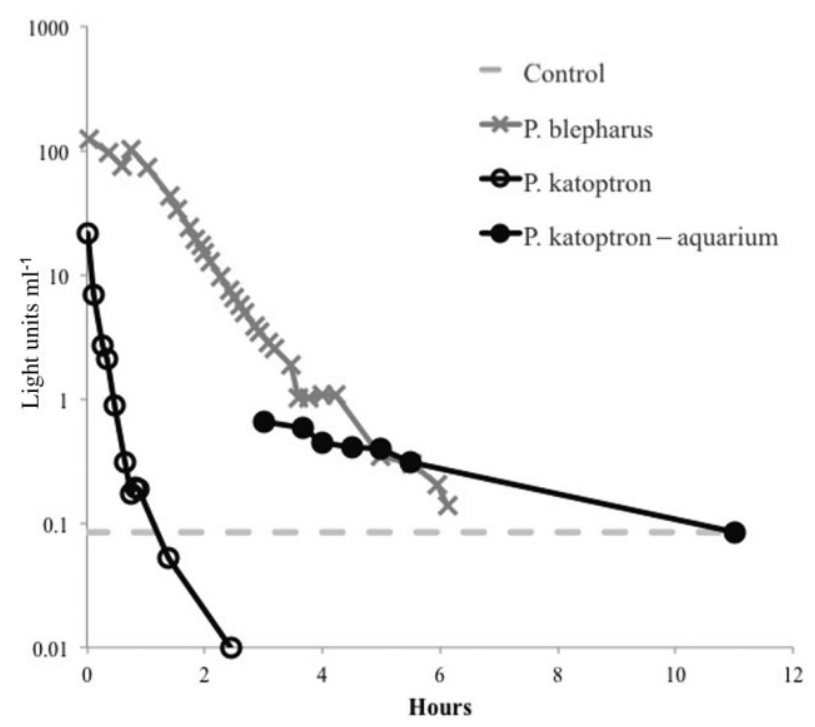

Fig. 1. Luminescence of ' $\mathrm{Ca}$. Photodesmus' species in seawater over time. Seawater samples were taken from tanks containing fish, and the luminescence of the water was monitored at intervals until readings reached control levels. Samples 'P. blepharus' and 'P. katoptron' were taken from water containing single fish of the host species Photoblepharon palpebratus and Anomalops katoptron respectively. These fish were collected in Vanuatu and had been shipped overnight from Los Angeles, CA, USA, to Ann Arbor, MI USA. They had been in the seawater sample (approximately $1 \mathrm{~L}$ volume) for approximately 18-28 h, sufficient time for symbiotic bacteria to build up in the water (Haygood et al., 1984), and had been starved for multiple days during shipping, decreasing the number of gut microbes likely to be in the water. The sample ' $P$. katoptron - aquarium' came from a tank at the Toledo Zoo that contained approximately 15 luminous $A$. katoptron individuals. Amplification by PCR of the luminescence gene luxA from the aquarium water only recovered ' $\mathrm{Ca}$. Photodesmus katoptron' sequences, suggesting that other luminous bacteria were not present in high numbers in the sample (data not shown). The 'Control' line is the average of seven readings taken during the course of each observation from a sample of sterile artificial seawater. Luminescence readings were taken from $1 \mathrm{ml}$ of water with a Turner Designs TD 20/20 luminometer (Sunnyvale, CA, USA).

facultative luminous symbionts, anomalopid symbionts are extracellular and densely packed within a specialized structure called the light organ (Kessel, 1977). The bacteria from two anomalopid species are known to be continuously released into the surrounding seawater through pores on the light organ surface and persist in seawater for at least hours (Haygood et al., 1984; Nealson et al., 1984). However, the symbiont species ' $\mathrm{Ca}$. Photodesmus katoptron', which has not been tested for persistence in seawater, is not thought to establish free-living populations (Hendry et al., in press). It is not known how new generations of anomalopids acquire bacteria, but no support has been found for direct vertical transmission through eggs (Haygood, 1993). Because of the environmental persistence of the bacteria and the apparent lack of transmission through eggs, larval anomalopid fish are thought to acquire bacteria from the environment (Haygood et al., 1984; Haygood, 1993; Hendry et al., in press). If anomalopid symbionts are environmentally acquired, bacteria might not show patterns of codivergence with hosts and different host species may not have different species of bacteria, especially if hosts overlap in geographic range and could acquire bacteria from the same environmental pool. First, to test that the obligate symbiont 'Ca. Photodesmus katoptron' could be acquired from the environment we measured luminescence of symbionts in water over time as an indication of persistence. Then, to determine the phylogenetic distance between anomalopid symbionts and test for a pattern of codivergence, we performed phylogenetic analyses on the bacteria symbiotic with multiple anomalopid species.

There are nine described anomalopid flashlight fish species (Froese and Pauly, 2013). The symbionts of four species - Anomalops katoptron, Kryptophanaron alfredi, Photoblepharon palpebratus and P. steinitzi - are included in analyses here. These species represent a wide geographic range: $A$. katoptron is found in the eastern Indian Ocean and co-occurs with $P$. palpebratus in the southern Pacific Ocean; $P$. steinitzi occurs in the Red Sea and western Indian Ocean; and $K$. alfredi is found in the Caribbean (McCosker and Rosenblatt, 1987; Johnson and Rosenblatt, 1988; Rosenblatt and Johnson, 1991; Baldwin et al., 1997; Johnson et al., 2001; Ho and Johnson, 2012; Froese and Pauly, 2013). Because anomalopid species are difficult to acquire and their symbionts are not culturable (Herring and Morin, 1978; Haygood, 1993), only the bacteria from one host species, A. katoptron, have been well studied. In the current study, we sequenced multiple protein-coding genes for symbionts of two additional fish species, P. palpebratus and $P$. steinitzi, to determine the phylogenetic divergence between symbionts of different host species.

\section{Results and discussion}

\section{Environmental persistence of 'Ca. Photodesmus'}

Previous studies demonstrated that the symbionts of two anomalopids, P. palpebratus and $K$. alfredi, are continually released from light organs of the fish and remain luminous, and therefore alive, in seawater for short periods of time (Haygood et al., 1984; Nealson et al., 1984). Here we show that the same is true of ' $C a$. Photodesmus katoptron', the bacterial symbiont obligately dependent on $A$. katoptron. Seawater in which individual specimens of $P$. palpebratus and $A$. katoptron had been kept showed readily detectable luminescence, the levels of which rapidly declined after removal of the fish (Fig. 1). The decline of luminescence observed here for the $P$. palpebratus samples is similar overall to that shown 
previously (Haygood et al., 1984), except that here luminescence remained detectable for a longer time $(6 \mathrm{~h}$ compared with $1.5 \mathrm{~h}$ ). The rate of decline in luminescence for A. katoptron samples was faster in the case of seawater containing one starved specimen of $A$. katoptron than in seawater from a stably maintained tank of healthy A. katoptron (Fig. 1). We speculate that the health of the host may influence the physiological state of the bacteria, with healthier fish allowing symbionts to persist longer outside of the host. These results, together with those of Haygood and colleagues (1984) and Nealson and colleagues (1984), indicate that symbiotic bacteria are released into the seawater from light organs of $P$. palpebratus, $K$. alfredi and $A$. katoptron and that these bacteria can persist in a viable state in the environment for periods of time up to at least a few hours.

\section{Phylogenetic support for 'Ca. Photodesmus'}

Both maximum-likelihood (ML) and Bayesian (BA) analyses recover a monophyletic clade for 'Ca. Photodesmus'. This result affirms previous work demonstrating that anomalopid symbionts represent a genus, 'Candidatus Photodesmus' (Greek: photo = light, desmus = servant) within the family Vibrionaceae (Hendry and Dunlap, 2011). The housekeeping gene ML tree (Fig. 2A) also places ' $\mathrm{Ca}$. Photodesmus' as sister to the genus Vibrio, consistent with earlier findings (Hendry and Dunlap, 2011). Of note is the fact that very low support is found for the clade Vibrio as currently configured. The BA housekeeping gene analysis differed slightly in that the BA tree (not shown) could not resolve the relationship between the anomalopid symbiont clade and the Vibrio clade, instead finding a polytomy. This ambiguity, along with the low support for the clade Vibrio in the ML tree, suggests that genus Vibrio is paraphyletic. Both ML and BA analyses of lux genes resolved identical topologies with ' $\mathrm{Ca}$. Photodesmus' as divergent from other Vibrionaceae genera and sister to Vibrio (Fig. 2B). The high phylogenetic distance separating anomalopid symbionts and relatives is consistent with obligate host dependence, as obligate symbionts often evolve at a faster rate than freeliving relatives (Moran, 1996; Woolfit and Bromham, 2003). The long branch leading to the ' $\mathrm{Ca}$. Photodesmus' clade (Fig. 2A) therefore suggests that obligate dependence evolved in the clade before the split of the bacterial lineages included here.

\section{Divergent symbiont species in different anomalopid genera}

Phylogenetic analyses and nucleotide sequence similarity both demonstrate that fish species of the genus Photoblepharon possess the same symbiont species but other fish genera have different bacterial species. Bacteria from the hosts P. palpebratus and P. steinitzi are closely related with strong support (Fig. 2). Consistent with this, the 16S rRNA gene sequences of bacteria from these two hosts show $99.6 \%$ identity, indicating that they are likely the same species. The bacteria symbiotic with Photoblepharon species were resolved as more divergent from the A. katoptron symbiont ' $\mathrm{Ca}$. Photodesmus katoptron' than is typical of other bacterial species in the family (Fig. 2). The $16 \mathrm{~S}$ sequences of the P. palpebratus and $P$. steinitzi symbionts are $94.8 \%$ identical to that of 'Ca. Photodesmus katoptron', a value that is lower than a commonly applied cut-off of $97 \%$ identity as well as the more stringent cut-off of $95 \%$ for species assignment (Stackebrandt and Goebel, 1994). The $16 S$ identity and the long branches that separate the Photoblepharon symbionts from ' $\mathrm{Ca}$. Photodesmus katoptron' in all analyses support the creation of a new species designation for the Photoblepharon symbionts. We propose the name 'Candidatus Photodesmus blepharus' (Greek: blephar = eyelid) after the host genus, which is so named for the lid-like structure individuals raise over the light organ to control light emission. Only the $16 \mathrm{~S}$ sequence is available for bacteria from the fourth species of host included here, K. alfredi. However, the $16 \mathrm{~S}$ identity between $\mathrm{K}$. alfredi symbionts and ' $\mathrm{Ca}$. Photodesmus katoptron', at $94.3 \%$, is also under $95 \%$, and long branches separate the $K$. alfredi symbiont from other bacteria, indicating that the fish genus Kryptophanaron likely also possesses a distinct species of symbiotic bacteria. These results demonstrate that different genera of anomalopids harbour different species of bacteria in their light organs. The fact that P. palpebratus and P. steinitzi harbour the same bacterial species is intriguing given the wide geographic separation and non-overlapping ranges of these fish - Pacific Ocean and western Indian Ocean respectively (Froese and Pauly, 2013). A recent speciation event in the fish, with insufficient time for symbiont evolutionary divergence to occur, could account for this crosshost-species bacterial specificity.

On the other hand, geographically co-occurring anomalopids harbour different species of symbiotic bacteria. The fish species $A$. katoptron and $P$. palpebratus co-occur for much of their range (southern Pacific Ocean, Philippines to Vanuatu) and are often collected in the same time and location (Wolfe and Haygood, 1991; T. A. Hendry, pers. obs.). Despite this proximity, A. katoptron and $P$. palpebratus collected at the same location harbour divergent symbionts that group with the species 'Ca. Photodesmus katoptron' and 'Ca. Photodesmus blepharus' respectively, suggesting a species-specific interaction (Fig. 3). However, because anomalopid fish are difficult to obtain, these conclusions are drawn from relatively few samples; it is possible that this pattern could 

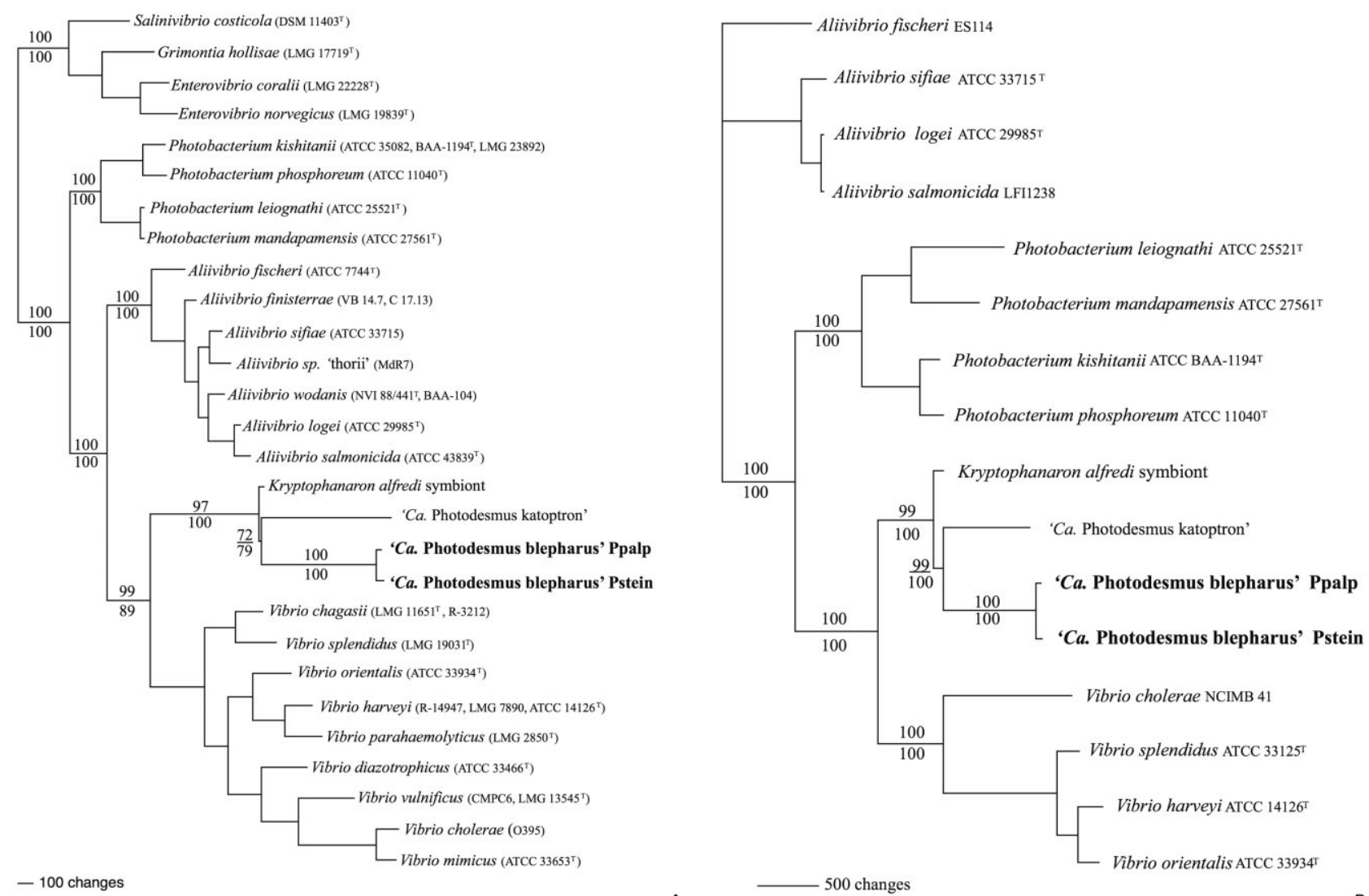

A

Fig. 2. Maximum-likelihood trees of flashlight fish symbionts and relatives.

A. Best tree based on housekeeping genes (16S rRNA gene, atpA, gapA, gyrB, pyrH, recA, rpoA and topA).

B. Best tree based on lux operon genes (IUXCDABEG).

Maximum-likelihood bootstrap numbers are shown above branches and Bayesian posterior probabilities are shown below. Strain designations follow taxon names. Taxa with new sequences are shown in bold. 'Ppalp' refers to symbionts isolated from P. palpebratus, and 'Pstein' indicates symbiont isolates from $P$. steinitzi. Accession numbers for sequences taken from GenBank can be found in Hendry and Dunlap (2011). New sequences used in this study were obtained from whole-genome lllumina sequencing of the $P$. palpebratus symbiont DNA and PCR amplification of the P. steinitzi symbiont DNA. For the P. palpebratus symbionts, four specimens (Ppalp.1-Ppalp.4) were collected from coastal waters in the Republic of Vanuatu in 2011, and DNA was extracted as in Hendry and Dunlap (2011). DNA from one light organ of each specimen was combined for sequencing. Very little polymorphism exists within the symbiont of a host species (Hendry and Dunlap, 2011; T. A. Hendry and P. V. Dunlap, unpubl. data), so sequences obtained from the combined samples should not be significantly different than if they had come from an individual. Illumina reads were assembled in Mira3 (Chevreux et al., 2002) by staff of the University of Michigan Collaborative Computing and Data Unit Bioinformatics Core. DNA from the P. steinitzi symbiont came from the sample described in Wolfe and Haygood (1991); the fish (Pstein.1) was obtained from the Coral World aquarium in Eilat, Israel, in 1987 and was likely collected from around Dahab on the Sinai peninsula. Previous work has found that both light organs of an individual contain monoclonal bacteria of the same genotype, so DNA from the $P$. steinitzi sample can be considered one strain. PCR amplification of $P$. steinitzi symbiont loci followed Hendry and Dunlap (2011). GenBank accession numbers for new sequences obtained in this study from the P. palpebratus symbiont (the 16S rRNA gene, atpA, gapA, gyrB, pyrH, recA, rpoA, topA and luxCDABEG) are JQ993843-JQ993856, and those from the P. steinitzi symbiont (the 16S rRNA gene, gapA, gyrB, pyrH, recA, rpoA, topA and luxCDAEG) are JQ993857-JQ993867. Phylogenetic analysis methods follow Hendry and Dunlap (2011). For housekeeping genes, a concatenated gene matrix was analysed using maximum likelihood in Garli (Zwickl, 2006) under the GTR $+I+\Gamma$ model. The lux operon was analysed as one locus, with non-coding regions removed, using the GTR $+I+\Gamma$ model. For both matrices, 1000 bootstrap replicates were performed, with each run for 1000 generations. For Bayesian analyses, each gene was analysed in MRBAYES v3.1.2 (Huelsenbeck and Ronquist, 2001) using the GTR $+\mathrm{I}+\Gamma$ model over 100000 generations, sampling every 100 generations.

change with more sampling, though the genetic distance between 'Ca. Photodesmus blepharus' and 'Ca. Photodesmus katoptron' suggests that the difference may be robust. In contrast, strains of facultatively symbiotic luminous bacteria, such as Aliivibrio fischeri, Photobacterium leiognathi and P. mandapamensis, often do not cluster tightly phylogenetically with other strains isolated from the same host species (Fig. 3). Compared to anomalopid symbionts, different strains of $A$. fischeri, $P$. leiognathi and $P$. mandapamensis from different hosts or different geographic locations vary little in 16S rRNA gene sequence (Fig. 3). Geographic isolation between host lineages is not a likely explanation for the high phylogenetic divergence observed in anomalopid symbionts, because host 


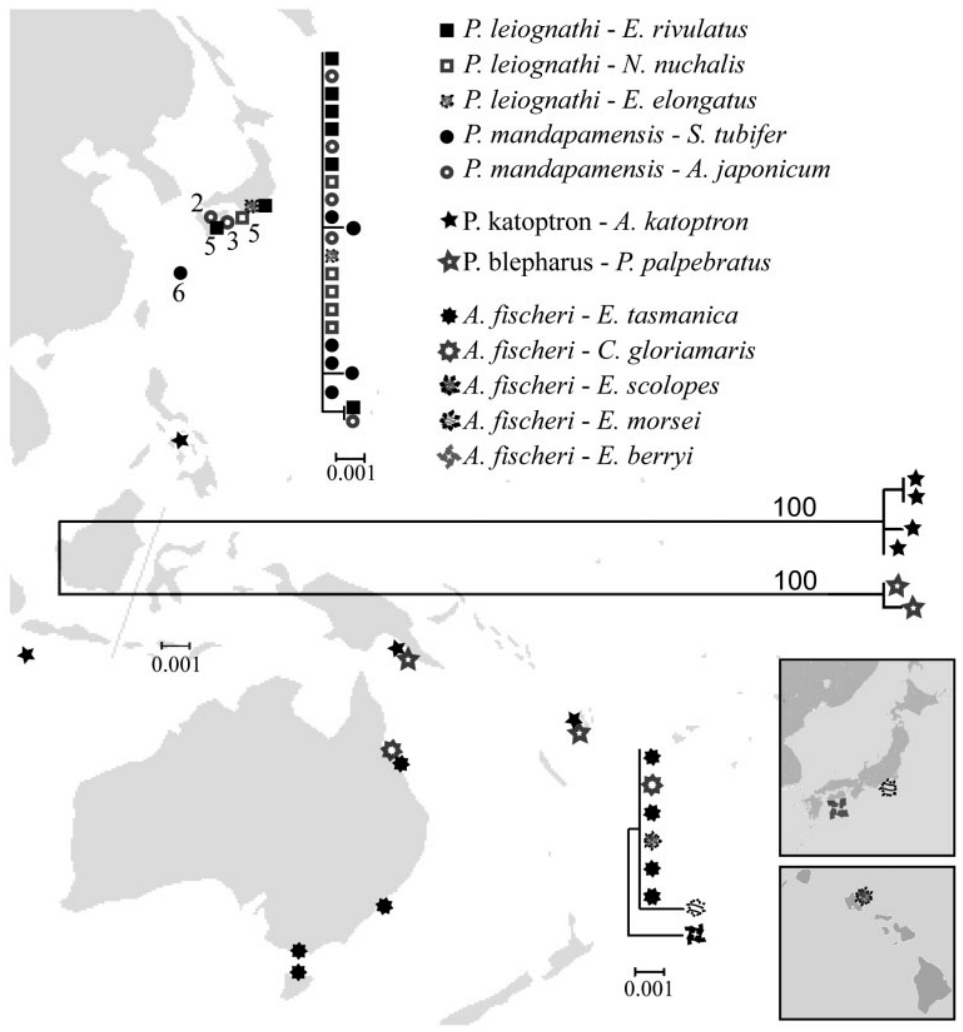

Fig. 3. Divergence between strains from different host genera for facultative symbionts versus ' $C a$. Photodesmus' species. The legend indicates bacterial species (left) and host species (right). Locations for host collections are shown on the map of the western Pacific Ocean with insert maps of Japan and Hawaii, USA, for some A. fischeri strains. Numbers placed near symbols indicate the number of strains isolated from the same host species at that location. We note that the collections at Papua New Guinea and Vanuatu each yielded $A$. katoptron and P. palpebratus specimens collected at the same site and time. Strains from the following host species were included: Equulites rivulatus, Nuchequula nuchalis, Equulites elongatus, Siphamia tubifer, Acropoma japonicum, Anomalops katoptron, Photoblepharon palpebratus, Euprymna tasmanica, Cleidopus gloriamaris, Euprymna scolopes, Euprymna morsei, Euprymna berryi. Maximum-likelihood trees were generated in MEGA5 (Tamura et al., 2011) using 16S sequences taken from GenBank or generated for this study for the following strains: 'Ca. P. katoptron' strains = Akat2007.1.1 (Hendry and Dunlap, 2011), A. katoptron symbiont (Haygood and Distel, 1993) and Akat8 (accession KF360256; this study); Kryptophanaron alfredi symbiont = Kryptophanaron alfredi symbiont (Haygood and Distel, 1993); 'Ca. P.

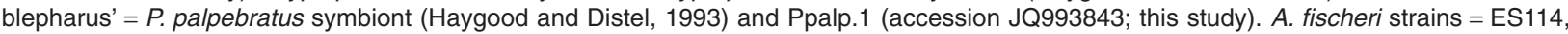
ET101, ET301, ET401, CG101, EM17, EB12 (Nishiguchi and Nair, 2003) and etasm.1.1 (Urbanczyk et al., 2007). P. leiognathi and P. mandapamensis strains = lelon.1.1, Irivu.1.1 (Dunlap et al., 2004), svers.1.1 (Kaeding et al., 2007), LC1-087, LC1-093, LC1-097, LC1-099, LC1-101, LC1-1113, LC1-1133, LC1-023, LC1-026, LC1-036, LC1-038, LC1-046, LC1-1275, LC1-1276, LC1-12767, LC1-1283, LC11296, AK2, AK5, AK7 (Wada et al., 2006). One thousand bootstrap replicates were performed in analyses, and only bootstrap values over 70 are shown on branches. All scale bars are equal and represent 0.001 substitutions per site.

species that co-occur consistently have different bacteria. Therefore, the species-specificity of $A$. katoptron, $P$. palpebratus and their symbionts likely has another explanation.

\section{Conclusions and evolutionary implications}

The bacterial species/host genus-level specificity of anomalopids and their symbiotic bacteria is consistent with obligate host dependence, and it contrasts with low levels of within-species specificity found in facultative luminous symbionts. The deep evolutionary divergence between symbionts of geographically co-occurring anomalopid hosts suggests that the bacteria are transmitted vertically. However, transmission could be either directly vertical, from parent to offspring, or pseudovertical, from bacteria left in the environment by adults (Bright and Bulgheresi, 2010; Sachs et al., 2011). The latter transmission mode has been suggested for anomalopids by previous research (Haygood, 1993; Hendry et al., in press) and is supported here and previously (Haygood et al., 1984; Nealson et al., 1984) by the findings that the bacteria are released from light organs into and can persist for at least a brief time in seawater. If $A$. katoptron and $P$. palpebratus larval fish develop separately and the symbiont of each species does not disperse far enough to reach larval fish of the other species, pseudovertical transmission alone could account for the pattern of 
Hosts

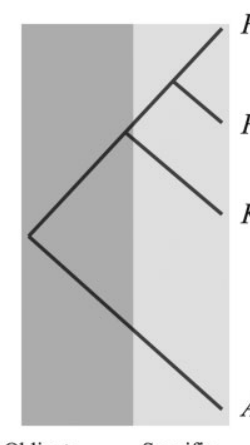

Obligate Specific

Non-specific Codiverging
Symbionts

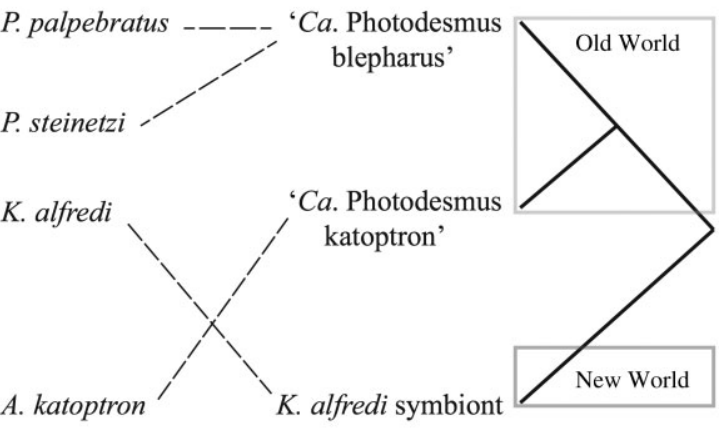

bacterial evolution observed here. Alternatively, fish could encounter bacteria released into the environment by both species, but either the fish or the bacteria could have molecular mechanisms that lead to species-specific interactions and allow sympatric symbiont divergence. 'Candidatus Photodesmus' symbiont species show signatures of high levels of genetic drift (Hendry and Dunlap, 2011; Hendry et al., in press). It is possible that genes needed to colonize certain host species would be lost by chance in some lineages, making them specific to a subset of hosts. Alternatively, gene loss in bacterial lineages might make them inferior symbionts to some host species, imposing selection on the host or bacterium to prevent colonization. Gene content or gene expression comparisons of multiple symbiont species could provide insight on the possible functional basis for this specificity.

Obligate intracellular symbionts often show codivergence and congruent phylogenetic topologies with hosts due to strict vertical transmission (Clark et al., 2000; Sachs et al., 2011). The number of host-bacterium pairs included here is too small to fully test for codivergence of flashlight fish and their symbionts, but the topology resolved for bacteria does not mirror the phylogeny of the host fish. The current host phylogeny, based on morphological characters, places the genera Kryptophanaron and Photoblepharon as more closely related to each other than they are to Anomalops (Baldwin et al., 1997), whereas the bacterial phylogeny resolves Anomalops and Photoblepharon symbionts as sister species to the exclusion of the Kryptophanaron symbiont, with high support (Fig. 4). If anomalopid symbionts are vertically transmitted, as the evidence suggests, they would be expected to codiverge with their individual hosts like other obligate symbionts (Clark et al., 2000; Sachs et al., 2011). However, the non-congruent phylogenies shown here (Fig. 4) contradict codivergence between hosts and bacteria. Several possible explanations exist for why this pattern could arise in spite of codivergence, such as an incorrect host phylogeny or multiple evolutions of
Fig. 4. Cladograms comparing anomalopid host phylogeny (left) and anomalopid symbiont phylogeny (right) (Baldwin et al., 1997; Johnson et al., 2001). Dashed lines represent host-symbiont relationships. Shown is a possible scenario for explaining the lack of congruence between phylogenies, in which obligate dependence in anomalopid symbionts evolved before specificity. We note that the host phylogeny is unrooted, but species that would further separate $A$. katoptron from $K$. alfredi have been left off the tree, as they were not included in analyses here (Baldwin et al., 1997). The symbiont clade is rooted based on relatives (Fig. 2), and therefore ' $\mathrm{Ca}$. Photodesmus katoptron' and ' $\mathrm{Ca}$.

Photodesmus blepharus' are sister species. obligate dependence and host shifts (Haygood and Distel, 1993). Alternatively, the fact that Old World symbionts ('Ca. Photodesmus katoptron' and 'Ca. Photodesmus blepharus') are more closely related to each other than they are to the New World symbiont (the K. alfredi symbiont) could suggest that specificity evolved more recently than the origin of the symbiosis (Fig. 4). The long branch separating the flashlight fish symbionts sampled here from relatives suggests that obligate dependence, and therefore accelerated evolution, evolved in the ancestral anomalopid symbiont. However, we can speculate that the ancestral obligate symbiont would not necessarily have codiverged with the host. It is possible that all bacteria maintained the ability to colonize multiple host species until after the separation of Old World and New World hosts and that bacteria have subsequently codiverged with hosts. In addition to demonstrating specificity, the results presented here suggest that codivergence between bacteria and hosts may have occurred after host speciation had begun rather than with the origin of the symbiosis. To fully test for codivergence, a molecular analysis of anomalopids to confirm the phylogenetic relationships between hosts and the addition of more symbiont sequences will be needed.

\section{Acknowledgements}

We thank M. G. Haygood for the generous gift of $P$. steinitzi symbiont DNA. We appreciate the help of J. Hemdal and the Toledo Zoo for access to aquarium tank water. We also thank the staff of the University of Michigan Sequencing Core for DNA sequencing and advice and J. R. de Wet of the University of Michigan Bioinformatics Analysis Core for carrying out sequence assembly. The assistance of M. J. Sheehan and A. Gould with sample collection is also appreciated. G. Norton of Sustainable Reef Suppliers, B. Remmer of Sea Dwelling Creatures, and Fish Doctors Aquarium provided assistance in obtaining P. palpebratus specimens. Departmental block grant awards from the University of Michigan Department of Ecology and Evolutionary Biology funded this work. 


\section{References}

Ast, J.C., Urbanczyk, H., and Dunlap, P.V. (2007) Natural merodiploidy of the lux-rib operon of Photobacterium leiognathi from coastal waters of Honshu, Japan. $J$ Bacteriol 189: 6148-6158.

Baldwin, C.C., Johnson, G.D., and Paxton, J.R. (1997) Protoblepharon rosenblatti, a new genus and species of flashlight fish (Beryciformes: Anomalopidae) from the tropical South Pacific, with comments on anomalopid phylogeny. Proc Biol Soc Wash 110: 373-383.

Bright, M., and Bulgheresi, S. (2010) A complex journey: transmission of microbial symbionts. Nat Rev Microbiol 8: 218-230.

Chevreux, B., Pfisterer, T., and Suhai, S. (2002) In Genomics and Proteomics - Functional and Computational Aspects. Suhai, S. (ed.). New York: Kluwer Academic Publishers, pp. 51-65.

Clark, M.A., Moran, N.A., Baumann, P., and Wernegreen, J.J. (2000) Cospeciation between bacterial endosymbionts (Buchnera) and a recent radiation of aphids (Uroleucon) and pitfalls of testing for phylogenetic congruence. Evolution 54: 517-525.

Dunlap, P.V., and Urbanczyk, H. (2013) Luminous bacteria. In The Prokaryotes - Prokaryotic Physiology and Biochemistry. Rosenberg, E., DeLong, E.F., Lory, S., Stackebrandt, E., and Thompson, F. (eds). Berlin: Springer-Verlag, pp. 495-528.

Dunlap, P.V., Jiemjit, A., Ast, J.C., Pearce, M.M., Marques, R.R., and Lavilla-Pitogo, C.R. (2004) Genomic polymorphism in symbiotic populations of Photobacterium leiognathi. Environ Microbiol 6: 145-158.

Dunlap, P.V., Ast, J.C., Kimura, S., Fukui, A., Yoshino, T., and Endo, H. (2007) Phylogenetic analysis of host-symbiont specificity and codivergence in bioluminescent symbioses. Cladistics 23: 507-532.

Dunlap, P.V., Davis, K.M., Tomiyama, T., Fujino, M., and Fukui, A. (2008) Developmental and microbiological analysis of the inception of bioluminescent symbiosis in the marine fish Nuchequula nuchalis (Perciformes: Leiognathidae). Appl Environ Microbiol 74: 74717481.

Dunlap, P.V., Gould, A.L., Wittenrich, M.L., and Nakamura, M. (2012) Initiation of bioluminescent symbiosis in the bacterially luminous coral reef fish Siphamia versicolor (Perciformes: Apogonidae). J Fish Biol 81: 1340-1356.

Froese, R., and Pauly, D. (2013) FishBase. URL http:// www.fishbase.org.

Haygood, M.G. (1993) Light organ symbioses in fishes. Crit Rev Microbiol 19: 191-216.

Haygood, M.G., and Distel, D.L. (1993) Bioluminescent symbionts of flashlight fishes and deep-sea anglerfishes form unique lineages related to the genus Vibrio. Nature 363: 154-156.

Haygood, M.G., Tebo, B.M., and Nealson, K.H. (1984) Luminous bacteria of a monocentrid fish (Monocentris japonicus) and 2 anomalopid fishes (Photoblepharon palpebratus and Kryptophanaron alfredi) - population sizes and growth within the light organs, and rates of release into the seawater. Mar Biol 78: 249-254.

Hendry, T.A., and Dunlap, P.V. (2011) The uncultured luminous symbiont of Anomalops katoptron (Beryciformes: Anomalopidae) represents a new bacterial genus. Mol Phylogenet Evol 61: 834-843.

Hendry, T.A., de Wet, J.R., and Dunlap, P.V. (in press) Genomic signatures of obligate host dependence in the luminous bacterial symbiont of a vertebrate. Environ Microbiol published online 8 Nov 2013. doi:10.1111/14622920.12302.

Herring, P.J., and Morin, J.G. (1978) Bioluminescence in fishes. In Bioluminescence in Action. Herring, P.J. (ed.). London: Academic Press, pp. 273-329.

Ho, H.-C., and Johnson, G.D. (2012) Protoblepharon mccoskeri, a new flashlight fish from eastern Taiwan (Teleostei: Anomalopidae). Zootaxa 3479: 77-87.

Huelsenbeck, J.P., and Ronquist, F. (2001) MRBAYES: Bayesian inference of phylogenetic trees. Bioinformatics 17: 754-755.

Johnson, G.D., and Rosenblatt, R.H. (1988) Mechanisms of light organ occlusion in flashlight fishes, family Anomalopidae (Teleostei, Beryciformes), and the evolution of the group. Zool J Linn Soc 94: 65-96.

Johnson, G.D., Seeto, J., and Rosenblatt, R.H. (2001) Parmops echinatus, a new species of flashlight fish (Beryciformes: Anomalopidae) from Fiji. Proc Biol Soc Wash 114: 497-500.

Kaeding, A.J., Ast, J.C., Pearce, M.M., Urbanczyk, H., Kimura, S., Endo, H., et al. (2007) Phylogenetic diversity and cosymbiosis in the bioluminescent symbioses of 'Photobacterium mandapamensis'. Appl Environ Microbiol 73: 3173-3182.

Kessel, M. (1977) The ultrastructure of the relationship between the luminous organ of the teleost fish Photoblepharon palpebratus and its symbiotic bacteria. Cytobiologie 15: 145-158.

Lee, K., and Ruby, E.G. (1994) Effect of the squid host on the abundance and distribution of symbiotic Vibrio fischeri in nature. Appl Environ Microbiol 60: 1565-1571.

Leis, J.M., and Bullock, S. (1986) The luminous cardinalfish Siphamia (Pisces, Apogonidae): development of larvae and the luminous organ. In Indo-Pacific Fish Biology: Proceedings of the Second International Conference on IndoPacific Fish. Uyeno, T., Arai, R., Taniuchi, T., and Matsuura, K. (eds). Tokyo: Ichthyological Society of Japan, pp. 703714.

McCosker, J.E., and Rosenblatt, R.H. (1987) Notes on the biology, taxonomy, and distribution of flashlight fishes (Beryciformes, Anomalopidae). Jpn J Ichthyol 34: 157164.

McCutcheon, J.P., and Moran, N.A. (2012) Extreme genome reduction in symbiotic bacteria. Nat Rev Microbiol 10: 13-26.

Mandel, M.J., Wollenberg, M.S., Stabb, E.V., Visick, K.L., and Ruby, E.G. (2009) A single regulatory gene is sufficent to alter bacterial host range. Nature 458: 215218.

Moran, N.A. (1996) Accelerated evolution and Muller's ratchet in endosymbiotic bacteria. Proc Natl Acad Sci U S A 93: 2873-2878.

Nealson, K.H., Haygood, M.G., Tebo, B.M., Roman, M., Miller, E., and McCosker, J.E. (1984) Contribution of symbiotically luminous fishes to the occurrence and biolumi- 
nescence of luminous bacteria in seawater. Microb Ecol 10: $69-77$.

Nishiguchi, M.K., and Nair, V.S. (2003) Evolution of symbiosis in Vibrionaceae: a combined approach using molecular and physiology. Int J Syst Evol Microbiol 53: 2019-2026.

Nyholm, S.V., and McFall-Ngai, M.J. (2004) The winnowing: establishing the squid-Vibrio symbiosis. Nat Rev Microbiol 2: 632-642.

Preheim, S.P., Boucher, Y., Wildschutte, H., David, L.A., Veneziano, D., Alm, E.J., and Polz, M.F. (2011) Metapopulation structure of Vibrionaceae among coastal marine invertebrates. Environ Microbiol 13: 265-275.

Reen, F.J., Almagro-Morena, S., Usery, D., and Boyd, E.F. (2006) The genomic code: inferring Vibrionaceae niche specialization. Nat Rev Microbiol 4: 697-704.

Rosenblatt, R.H., and Johnson, G.D. (1991) Parmops coruscans, a new genus and species of flashlight fish (Beryciformes, Anomalopidae) from the south Pacific. Proc Biol Soc Wash 104: 328-334.

Sachs, J.L., Essenberg, C.J., and Turcotte, M.M. (2011) New paradigms for the evolution of beneficial infections. Trends Ecol Evol 26: 202-209.

Stackebrandt, E., and Goebel, B.M. (1994) Taxonomic note: a place for DNA-DNA reassociation and $16 \mathrm{~S}$ rRNA sequence analysis in the present species definition in bacteriology. Int J Syst Bacteriol 44: 846-849.

Tamura, K., Peterson, D., Peterson, N., Stecher, G., Nei, M., and Kumar, S. (2011) MEGA5: molecular evolutionary genetics analysis using maximum likelihood, evolutionary distance, and maximum parsimony methods. Mol Biol Evol 28: 2731-2739.

Thompson, J.R., Pacocha, S., Pharino, C., Klepac-Ceraj, V., Hunt, D.E., Benoit, J., et al. (2005) Genotypic diversity within a natural coastal bacterioplankton population. Science 307: 1311-1313.

Urbanczyk, H., Ast, J.C., Higgins, M.J., Carson, J., and Dunlap, P.V. (2007) Reclassification of Vibrio fischeri, Vibrio logei, Vibrio salmonicida and Vibrio wodanis as Aliivibrio fischeri gen. nov., comb. nov., Aliivibrio logei comb. nov., Aliivibrio salmonicida comb. nov. and Aliivibrio wodanis comb. nov. Int J Syst Evol Microbiol 57: 28232829.

Wada, M., Kamiya, A., Uchiyama, N., Yoshizawa, S., Kita-Tsukamoto, K., Ikejima, K., et al. (2006) LuxA gene of light organ symbionts of the bioluminescent fish Acropoma japonicum (Acropomatidae) and Siphamia versicolor (Apongonidae) forms a lineage closely related to that of Photobacterium leiognathi ssp. mandapamensis. FEMS Microbiol Lett 260: 186-192.

Wernegreen, J.J. (2002) Genome evolution in bacterial endosymbionts of insects. Nat Rev Genet 3: 850-861.

Wernegreen, J.J., and Moran, N.A. (2004) Evidence for genetic drift in endosymbionts (Buchnera): analyses of protein-coding genes. Mol Biol Evol 16: 83-97.

Wolfe, C.J., and Haygood, M.G. (1991) Restriction fragment length polymorphism analysis reveals high levels of genetic divergence among the light organ symbionts of flashlight fish. Biol Bull 181: 135-143.

Woolfit, M., and Bromham, L. (2003) Increased rates of sequence evolution in endosymbiotic bacteria and fungi with small effective population sizes. Mol Biol Evol 20: 1545-1555.

Zwickl, D.J. (2006) Genetic algorithm approaches for the phylogenetic analysis of large biological sequence datasets under the maximum likelihood criterion. PhD Thesis. Austin, TX: The University of Texas. 